\title{
La opción de propiedad pública en el rescate de
}

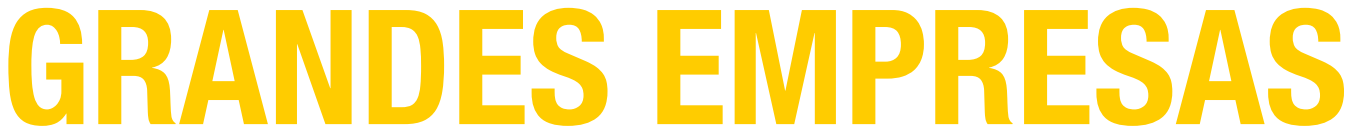

Lo que se pretende con este artículo es entrar a la acción quitando todo prejuicio ideológico, proponiendo que si el
Estado las va a rescatar, el plan de salvataje considere la propiedad pública de estas empresas, sin restricciones.

Eduardo Saavedra P., Ph.D. en Economía de Cornell University. Académico FEN-UAH y Director Académico del Centro Interdisciplinar de Políticas Públicas, $U A H$.

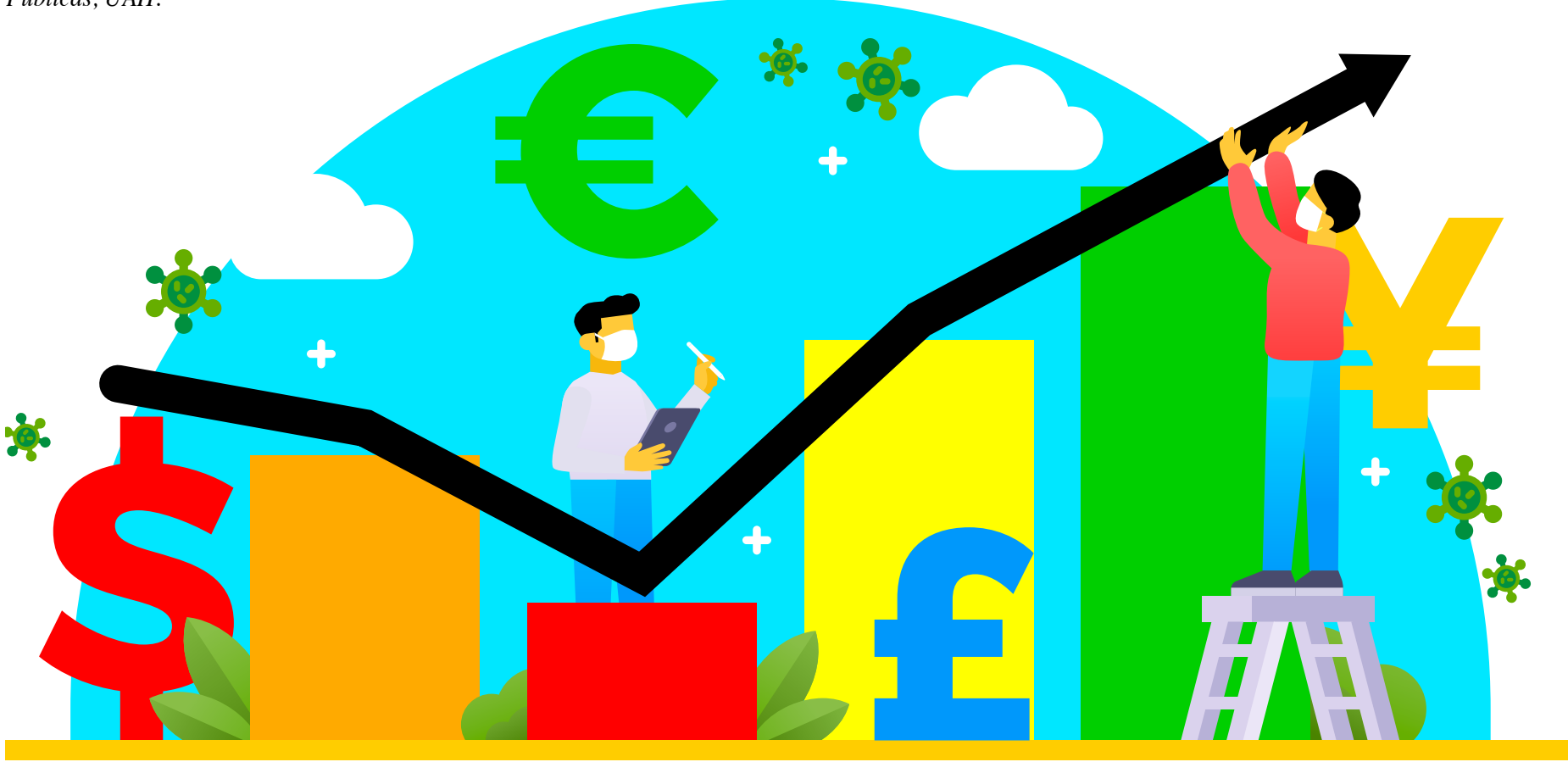

L a profunda crisis económica derivada de la pandemia del Covid-19 pone en jaque la continuidad de los negocios y la estabilidad del empleo. Grandes empresas en sectores tan diversos como transporte, particularmente aerolíneas, turismo e incluso el retail, han reducido sus ventas a niveles alarmantes, al punto de plantear abiertamente la necesidad de su rescate con fondos públicos, como se está estudiando en Estados Unidos y ya se ha hecho efectivo en Alemania con el rescate público de Lufthansa. Previo a tomar cualquier medida en esta línea debemos responder tres preguntas: ¿Tienen sentido estos rescates en una economía de mercado? ¿Son complementarios o sustitutos a otras opciones de financiamiento? ¿Debería hacerse vía propiedad pública o simplemente prestando recursos como lo hizo el Banco Central en el rescate de la banca hace cuatro décadas?

La primera pregunta no es retórica, ya que los ciudadanos estamos acostumbrados a ver que con las grandes empresas se opera a través de la lógica de "beneficios privados y pérdidas públicas", por lo que debe existir una razón de fondo para apoyar rescates billonarios. Las grandes empresas se caracterizan por contratar mucho empleo de manera directa, pero más aun de manera indirecta por los encadenamientos productivos que tienen hacia otras industrias, por lo que una quiebra masiva de estas empresas producirá serios desequilibrios macroeconómicos y enviará a la casa a cientos de miles de trabajadores, agudizándose de esta manera los problemas sociales que han quedado más que patentes desde el estallido social. La quiebra masiva de grandes empresas produce problemas que perduran por más tiempo que la crisis misma. Si desaparecen unas pocas empresas, las que queden detentarán mayor poder de mercado y podrían realizar prácticas anticompetitivas con daños irreversibles en los consumidores. Sin embargo, esa no es la peor noticia, sino que quiebren todas las empresas de un mismo mercado (piénsese de nuevo en aerolíneas o turismo) -o que para paliar la crisis és- tas desatiendan mercados particulares- lo que produciría mercados incompletos, es decir mercados en donde la demanda no es satisfecha por la inexistencia de la oferta. En este último caso el desastre hacia el resto de la economía sería mayúsculo, siendo la razón fundamental para apoyar iniciativas de rescate selectivo de grandes empresas ${ }^{1}$.

Una política de rescate de grandes empresas en crisis profundas no debe ir en detrimento de las opciones que las propias empresas tienen a su disposición, ya que éstas tienen acceso al crédito en mejores condiciones que las empresas de menor tamaño, en particular a través de la emisión de bonos y otros instrumentos de deuda. Esto es, todo indica que teniendo acceso al crédito bancario, las grandes empresas deberían priorizar estos otros instrumentos de deuda más baratos. Por ello, una política de rescate de grandes empresas no sólo debe ser selectiva, sino que debe configurarse como un complemento de las opciones que entrega el propio mercado de capitales.

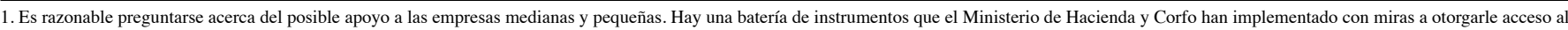

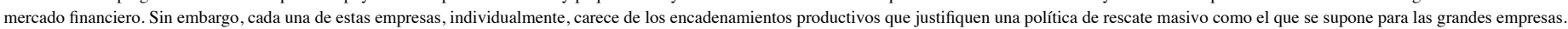
Algo de esto, junto a otros programas de apoyo en ejecución, son revisados en el artículo de Carlos García, en este mismo número. 
En Chile conocemos del rescate de la banca privada hecho por el Banco Central en enero de 1983, cuando el ente emisor evitó un colapso económico de tal magnitud que habría acabado con el sistema de pagos del país. Este rescate se implementó a través de deuda subordinada, inyectándose miles de millones de dólares a bancos técnicamente quebrados. En algunos casos los dueños simplemente perdieron toda la propiedad o sus derechos sobre el retorno de los activos, mientras que en otros casos los dueños originales sólo perdieron temporalmente dichos derechos. Ciertamente el Banco Central, parte del Estado de Chile, perdió mucho dinero en este rescate, porque lo hizo a tasas de interés muy por debajo de las de mercado y nunca se benefició de los posteriores aumentos de precios de las acciones de los bancos intervenidos que logró sacar adelante. El propio ente emisor estima que perdió en torno al $6 \%$ del PIB, esto es a los niveles actuales unos 18 mil millones de dólares.

Se ha debatido públicamente cómo debería hacerse actualmente un rescate de este tipo. Muy ideológicamente algunos se oponen a que el Estado adquiera participaciones accionarias de empresas privadas, reservando al Estado el ingrato de rol de prestamista y, de paso, apoyando la socialización de las pérdidas en tiempos de crisis y evitando que se socialicen sus ganancias cuando la crisis pase. Bajo este prisma de Estado subsidiario extremo se a todos los contribuyentes a perder dinero a manos llenas, sin que el Estado pueda recuperarlo con aquellas empresas que resistirán la crisis, pues éstas sólo pagarán su deuda y, seguramente, a módicos intereses que estarían lejos de ser los de mercado.

Debemos ser muy responsables con los fondos públicos, que son de todos los chilenos y tienen un elevado costo alternativo, especialmente en períodos de pandemia y recesión económica, por lo que el Estado debe asegurar que se maximizará su recuperación. De ser necesaria esta intervención, una mejor opción para nuestro país es que ésta se haga inyectando capital y accediendo a la propiedad de las empresas rescatadas bajo las mismas condiciones que los propietarios privados. Si finalmente algunas empresas quiebran, el Estado perderá su capital invertido, pero en aquellos casos en que las empresas logren sortear exitosamente la crisis, la evidencia indica que el valor de sus acciones subirá y el Estado obtendrá ganancias una vez que venda sus acciones. En la suma, un Estado que ingresa a la propiedad de las grandes empresas actúa como un inversionista que diversifica el riesgo, al estilo de capital semilla, por lo que unos pocos casos exitosos podrían más que compensar las pérdidas en aquellos casos en donde pierda su capital.

¿Cómo implementar el ingreso del Estado a la propiedad de las empresas rescatadas? Dos condiciones de borde son absolutamente imprescindibles. En primer lugar, más que ver esto como una oportunidad de negocios, que sin dudas lo sería, debe verse desde el prisma del Estado regulador
"Si desaparecen unas pocas empresas, las que queden detentarán mayor poder de mercado $y$ podrían realizar prácticas anticompetitivas con daños irreversibles en los consumidores"

que atiende al buen funcionamiento del mercado con una mirada País. Por ello el rescate no sólo debe ser selectivo, sino particularmente debe atender al menor impacto en la dinámica competitiva del mercado y teniendo como objetivo de largo plazo su funcionamiento una vez superada la crisis económica. En segundo lugar, una mirada de economía política nos obliga a equilibrar las tensiones que aparecen en los grupos de interés directamente relacionados con la solución, que resumimos en dos preguntas: ¿bajo qué condiciones los actuales dueños y controladores de las empresas rescatadas aceptarían al Estado como socio en sus empresas? y ¿bajo qué condiciones el Congreso aprobaría una ley de elevado quórum que permita al Estado ingresar a la propiedad de empresas privadas?

Teniendo en cuenta la mirada País y las tensiones de economía política señaladas, y suponiendo que el rescate se focaliza en sociedades anónimas abiertas, éste se debe valorizar a un precio de la acción pre crisis Covid-19, por ejemplo al precio del cierre del 30 de enero de 2020. Varias fórmulas son posibles, como por ejemplo la emisión de nuevas acciones que sean adquiridas por el Estado. Piénsese en una opción más simple, en que los dueños originales entregan parte de sus acciones al Estado. Bajo este esquema no lo harían al precio actual, pues en dicho caso lo podrían vender en bolsa y quedarse con su capital, luego necesariamente para suscitar su apoyo e inyectar nuevo capital a la empresa, el rescate debe hacerse a un precio mayor que el actual. Para evitar largas negociaciones y el siempre complejo caso a caso, una fecha concreta es más simple, más aun si es justamente antes de la pandemia, ya que el valor presente de los retornos que entregarán las acciones de la empresa rescatada en el largo plazo son razonablemente más cercanos al precio pre crisis que al actual. En efecto, aunque bajo este mecanismo se estaría pagando un sobreprecio, pues el precio de la acción a enero no tenía plenamente incorporado un pésimo 2020 producto de la pandemia, aun así el sesgo sería menor que pagando el precio actual, el que está totalmente influido por el pánico y el pesimismo propio de cuando se está en medio de la crisis.

Un diseño coherente requiere que este mecanismo de rescate incluya tres condiciones adicionales.
Lo primero es que los dueños actuales -aquellos que entregan sus acciones- tengan prioridad para recomprarlas, por lo que deben definirse hitos en que el Estado las sacará a remate, por ejemplo un tercio dentro de cinco años, otro tanto dentro de diez años y el tercio remanente en 15 años. Los dueños originales podrían ejercen su derecho prioritario de recompra tres meses antes de cumplido el hito, pagando el valor bolsa de las acciones que saldrán a remate al precio vigente. En segundo lugar, dependiendo del monto del salvataje, el Estado debe entrar a la propiedad de estas empresas sin restricciones como accionista, en particular en el nombramiento de directores, la toma de control de la empresa e incluso su eventual gestión. Por último, la administración como accionista de estas empresas debería quedar en manos del Sistema de Empresas Públicas y sus directores ser elegidos por el Sistema de Alta Dirección Pública, y no pensar en crear figuras ad hoc para las empresas rescatadas.

Para el caso en que haya grandes empresas rescatadas que no transan en bolsa, su valorización es más compleja aunque no imposible. Con todo, por simetría dicha valorización debe quedar supeditada a las condiciones de mercado de fines de enero de 2020. Una vez definido el precio por el cual se accede a la propiedad, que determina el porcentaje de esta, se deben definir igualmente los hitos que marcarán la recompra de esta participación. Tratándose de empresas que no transan en bolsa, el valor de éstas debe calcularse llegado cada hito. Si los dueños originales no ejercen su derecho de recompra en cualquiera de estos hitos, y por la dificultad de encontrar compradores si la participación es minoritaria, la participación que debía recomprarse deberá transformarse en deuda (al nuevo valor de la empresa) y ser pagada de acuerdo a las tasas de mercado en el mediano plazo, por ejemplo en un plazo no superior a unos ocho años. En otras palabras, los dueños actuales quedan amarrados a pagar la salida del Estado de su propiedad. Finalmente, los derechos del Estado como propietario y la administración del portafolio de estas empresas debe seguir el mismo criterio propuesto para las sociedades anónimas abiertas.

En conclusión, hay muchas maneras en que el Estado puede acudir al rescate de grandes empresas en tiempos de crisis extremas. Lo que se pretende con este artículo es entrar a la acción quitando todo prejuicio ideológico, proponiendo que si el Estado las va a rescatar, el plan de salvataje considere la propiedad pública de estas empresas, sin restricciones. La propuesta concreta explicada precedentemente es una de varias posibles, siendo lo importante la coherencia con que se diseña, la mirada País que debe tener el gobierno que la implemente y con los dos pies bien puestos en la realidad de modo de hacerse cargo de las tensiones de economía política que una decisión de este tenor trae consigo. $\mathbf{E}$ 